\title{
PREDICTING HOW CRACK TIP RESIDUAL STRESSES INFLUENCE BRITTLE FRACTURE
}

\author{
Saeid Hadidimoud, Ali Mirzaee-Sisan, Chris E. Truman and David J. Smith \\ Department of Mechanical Engineering, \\ University of Bristol, UK, BS8 1TR
}

\begin{abstract}
A probability distribution model, based on the local approach to fracture, has been developed and used for estimating cleavage fracture following prior loading (or warm pre-stressing) in two ferritic steels. Although there are many experimental studies it is not clear from these studies whether the generation of local residual stress and/or crack tip blunting as a result of prior loading contribute to the enhancement in toughness. We first identify the Weibull parameters required to match the experimental scatter in lower shelf toughness of the candidate steels. Second we use these parameters in finite element simulations of prior loading on the upper shelf followed by unloading and cooling to lower shelf temperatures to determine the probability of failure. The predictions are consistent with experimental scatter in toughness following WPS and provide a means of determining the relative importance of the crack tip residual stresses and crack tip blunting. We demonstrate that for our steels the crack tip residual stress is the pivotal feature in improving the fracture toughness following WPS. The paper finally discusses these results in the context of the nonuniqueness and the sensitivity of the Weibull parameters.
\end{abstract}

key words: local approach, brittle fracture, failure probability, warm pre-stressing, residual stress

\section{NOMENCLATURE}

a Crack length, mm

$a / W \quad$ crack/ligament ratio, -

$i \quad$ order number of specific specimen $(i=1, . ., N)$

$m \quad$ Weibull exponent, -

$N \quad$ total number of specimens (sample size)

$K_{0 f} \quad$ Reference toughness, MPa $\sqrt{\mathrm{m}}$

$K_{f} \quad$ Fracture toughness after WPS, MPa $\sqrt{m}$

$K_{\text {minf }} \quad$ Threshold toughness, MPa $\sqrt{\mathrm{m}}$

$K_{I C} \quad$ Fracture toughness, as-received condition $\mathrm{MPa} \sqrt{\mathrm{m}}_{\mathrm{m}}$

$P_{f} \quad$ Probability of failure, \%

$V_{0} \quad$ Reference volume, $\mathrm{mm}^{3}$

$\beta \quad$ toughness exponent

$\sigma_{f} \quad$ Fracture Stress, MPa

$\sigma_{\min } \quad$ Threshold stress, GPa

$\sigma_{l} \quad$ Maximum principal stress, $\mathrm{GPa}$

$\begin{array}{ll}\sigma_{u} & \text { Weibull reference stress, GPa } \\ \sigma_{w} & \text { Weibull stress, GPa }\end{array}$

\section{INTRODUCTION}

Enhancement in cleavage fracture toughness of pressure vessel steels loaded at lower shelf temperatures following pre-stressing at upper shelf and cooling (known as the warm pre-stress, WPS effect), is backed by extensive experimental evidence. [1,2]. Figure 1 provides a schematic illustration of the WPS effect on toughness. However it is not known to what extent this effect is due to localised residual stresses, crack tip blunting or a mixture of the two generated during pre-stressing. Studies by Reed and Knott [3,4] and Fowler [5] suggest that crack tip residual stresses are the dominating factor.

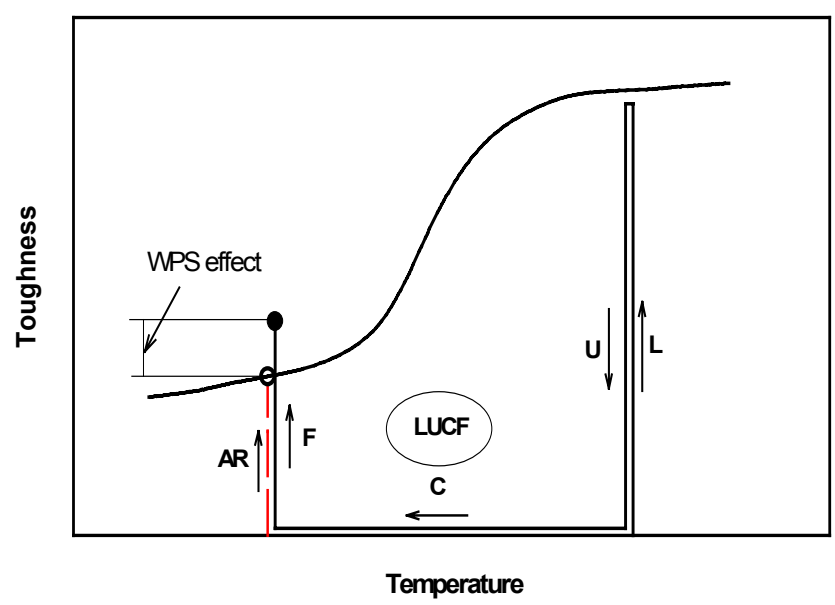

Fig. 1. Schematic presentation of WPS effect on low temperature cleavage fracture (Improvement of cleavage fracture toughness) 
Experimental observations indicate considerable uncertainty (wide scatter) in the cleavage fracture toughness of ferritic pressure vessel steels before and after WPS [6,7]. Statistical models mostly based on Weibull three and/or four parameter distributions are used to describe the scatter in the test results. The fracture load is expressed in terms of toughness $\left(K_{f}\right)$ for pre-cracked specimens and as fracture stress $\left(\sigma_{f}\right)$ for shallow notches. Theoretical models using near crack tip stress and strain fields have been used to predict the WPS effect. Models such as those developed by Curry [8] and Chell [9], combined with a local fracture criterion like that developed by Ritchie, Rice and Knott (RKR), were used by Fowler et al [7] to explore scatter in the WPS effect. They used a three-parameter Wallin equation to predict failure probability $\mathrm{P}_{\mathrm{f}}$ of two pressure vessel steels following warm prestressing. The equation is:

$$
P_{f}\left[K_{f}\right]=1-\exp \left[\left(\frac{K_{I c}-K_{\min f}}{K_{0 f}-K_{\min f}}\right)^{\beta}\right]
$$

where $\mathrm{K}_{\mathrm{Ic}}$ is the as-received fracture toughness, and the distribution parameters $\mathrm{K}_{\operatorname{minf}}$ and $\mathrm{K}_{0 \mathrm{f}}$ were determined using the Chell model for WPS. The shape parameter $\beta$ was chosen by Fowler et al [7] as a constant equal to 4 .

An alternative approach was developed by the Beremin group [10,11] using a local approach. This method uses the Weibull probability parameters fitted to fracture test results from round notched bars (RNB). In their round robin studies on micro-mechanical models, the European Structural Integrity Society (ESIS) suggest using the parameters fitted to the RNB test results to predict cleavage fracture in pre-cracked $\mathrm{C}(\mathrm{T})$ specimens [12]. In using the local approach the Weibull stress, $\sigma_{\mathrm{w}}$, is representative of failure conditions. The model is based on weakest link theory in the form of a Weibull probability distribution, where

$$
P_{f}\left[\sigma_{f}\right]=1-\exp \left[-\left(\frac{\sigma_{w}-\sigma_{\min }}{\sigma_{u}-\sigma_{\min }}\right)^{m}\right]
$$

and the Weibull stress $\sigma_{\mathrm{w}}$ is

$$
\sigma_{w}=\left[\frac{1}{V_{0}} \int \sigma_{1}^{m} d V\right]^{1 / m}
$$

The Weibull stress is a function of the shape parameter, $m$, and the reference volume $V_{0}$ and $\sigma_{1}$ is the maximum principal stress. The Weibull parameters are determined from experimental results. It should be noted that in both the Beremin and the ESIS studies the analyses were conducted assuming $\sigma_{\min }=0$. Beremin suggest that the reference volume, $\mathrm{V}_{0}$, is a volume equivalent to about ten grains of the material (e.g. $\mathrm{V}_{0}=0.001 \mathrm{~mm}^{3}$ ).

In this paper the influence of the local residual stresses arising from WPS is explored using a local approach for both pre-cracked specimens and round notched bars (RNB). A stress based model of the probability distribution, similar to the Beremin model, is used in finite element (FE) analyses together with the stress distribution under a specified loading condition at the crack tip within the plastic volume to calculate a characteristic stress. This in turn is used to estimate the probability of failure corresponding to the as-received state and the loading state following warm pre-stressing. First we summarise recent experimental results that explore the influence of WPS on two pressure vessel steels. Then the results of FE studies incorporating analyses for local failure probability are briefly described. These results are compared with the experimental findings; with the comparisons discussed in relation to the influence of the crack tip residual stresses.

\section{SUMMARY OF EXPERIMENTAL RESULTS}

Test results from two pressure vessel ferritic steels, A533B and (1) A508 are summarised here. Both steels were used in earlier test programmes by Smith and Garwood [6], Fowler [5], and Swankie[13] For the A533B steel, tests were carried out by Smith and Garwood [6] using single edge notch bend $(\mathrm{SE}(\mathrm{B}))$ containing fatigue pre-cracks with nominal $a / W=0.5$. Fourteen specimens in the as received conditions were fractured tested at $-170^{\circ} \mathrm{C}$ with another fourteen preloaded and unloaded at room temperature and then cooled and fractured at $-170^{\circ} \mathrm{C}$ (the LUCF loading cycle). The pre-loading level was equivalent to an elastic stress intensity factor of $120 \mathrm{MPa} \sqrt{\mathrm{m}}$. All tests at low temperature failed in a brittle manner by cleavage. Fracture toughness test results are shown in Fig. 2 with the failure probability $\mathrm{P}_{\mathrm{f}}$ determined using equation (4) [14].

$$
P_{f}=\frac{i-0.5}{N}
$$

where $\mathrm{N}$ is the total number of specimens, and $\mathrm{i}$ the order number.

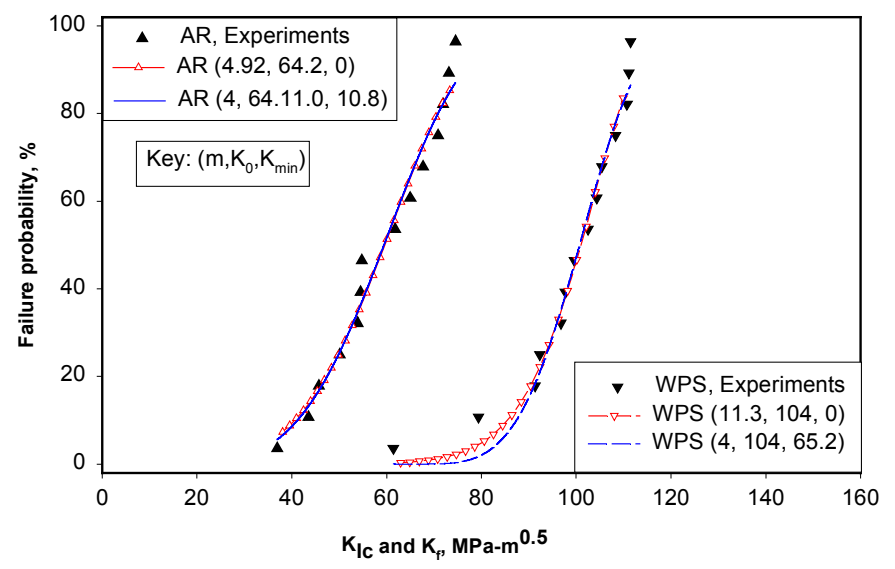

Fig. 2. Distribution of experimental as received and warm-pre-stressed test results for pre-cracked specimens using A533B pressure vessel steel at $-170^{\circ} \mathrm{C}$

Recent results for A508 steel using RNB specimens tested in the as-received state and after WPS at $-150^{\circ} \mathrm{C}$ are shown in Figure 3. 
Again, failure probability was determined using equation (3). Each specimen contained a circumferential U-shape notch with the radius of $1.25 \mathrm{~mm}$. The outer diameter and the diameter at the net section across the notch centre were 14 and $7.7 \mathrm{~mm}$ respectively. Nine tests for each loading state were tested. For the WPS tests, the preload level at room temperature was equivalent to a net section stress of $935 \mathrm{MPa}$. All tests at $-150^{\circ} \mathrm{C}$ failed by cleavage. Test results as shown in Fig. 3 are directly interpreted in terms of fracture stress against failure probability. The fracture stress was determined using the applied load divided by the measured final net section area.

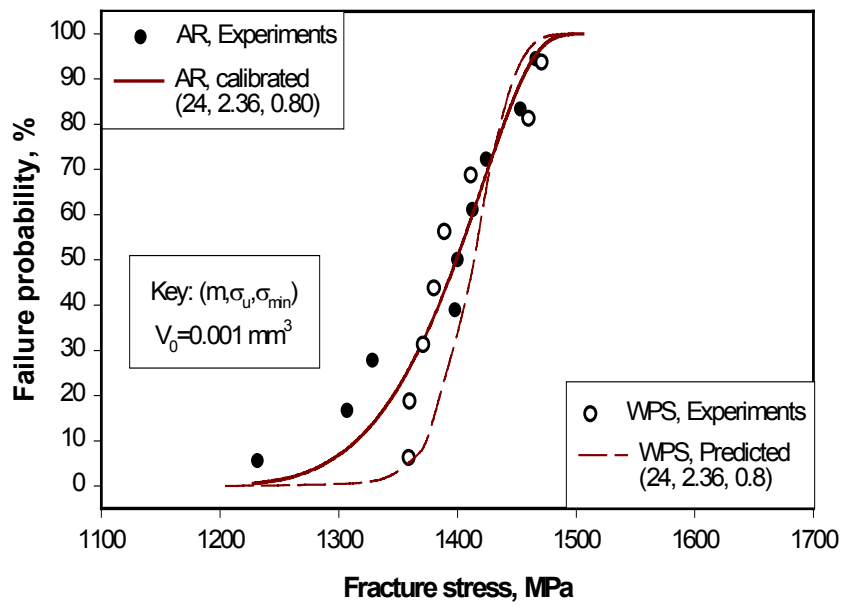

Fig. 3. Prediction of failure probability in the round notched bar specimens using A508 Steel at $-150^{\circ} \mathrm{C}$ following warm-pre-stressing

The experimental results from the pre-cracked specimens demonstrate that there is a considerable improvement in fracture toughness following WPS. Empirical curves using equation (1) are also shown in Figure 2, first with $K_{\min }=0$ and then with $K_{\min }$ as a free parameter. The resulting empirical curves reveal strong dependence on the shape parameter $\beta$ and $K_{\min }$. Consequently using either of the two parameters sets $\left[\left(\beta, K_{0}\right)\right.$ or $\left(K_{\min }, K_{0}\right.$ with fixed $\left.\left.\beta=4\right)\right]$ provides a fit of the same quality.

The experimental results from the RNB tests do not show the same level of improvement obtained from the pre-cracked tests. Rather the influence of WPS is only beneficial at lower levels of failure stress. The reason for this contrast between the pre-cracked and RNB specimens is explored later.

\section{FINITE ELEMENT STUDIES}

\section{FE Models}

Throughout the numerical finite element studies meshes were created in ABAQUS/CAE and then the analysis performed using the ABAQUS finite element code [15]. For the pre-cracked specimen a two-dimensional finite element model with a refined mesh around the crack tip was created. Due to symmetry only one half of the specimen was modelled. Eight noded quadratic elements with reduced integration were used and the element size at the crack tip did not exceed $0.05 \mathrm{~mm}$. For the RNB specimen axial symmetry allowed the use of axi-symmetric elements (iso-parametric quadratic eight noded with reduced integration) and due to the plane of symmetry at the notch tips only one half of the specimen was modelled. The smallest element size was less that $0.1 \mathrm{~mm}$. All analysis used elastic-plastic isotropic hardening material laws. For A533B steel the yield strengths $(0.2 \%$ offset $)$ are $528 \mathrm{MPa}$ and $877 \mathrm{MPa}$ at $20^{\circ} \mathrm{C}$ and $-170^{\circ} \mathrm{C}$ respectively. For A508 steel the yield strengths are $430 \mathrm{MPa}$ and $695 \mathrm{MPa}$ at $20^{\circ} \mathrm{C}$ and $-150^{\circ} \mathrm{C}$ respectively.

To estimate probability of fracture using equations (2) and (3), a routine ("Local") was written to perform the analysis using the results from the FE simulations. The integration volume was chosen as the region (elements) where plastic straining took place and $\sigma_{1}$ was the maximum principal stress. In each element the integration points where plasticity was reached were counted. This determined the fraction of the elements on the boundary of the plastic region that were included in the integration volume. Thus the plastic region was allowed to intersect the elements on the boundary and provide more accurate results for the characteristic Weibull stress. The procedure was repeated for each load increment in the FE analysis.

To implement equations (2) and (3) details of the four parameters $\left(\mathrm{m}, \mathrm{V}_{0}, \sigma_{\mathrm{u}}\right.$ and $\sigma_{\min }$ ) were required. The procedure for determining these parameters is described in the next section and later we describe results obtained from simulating WPS.

\section{Calibration of Weibull Parameters}

The process of calibrating the Weibull parameters has also been studied by Gao and co-workers [16]. Their results demonstrate that the four parameters $\left(\mathrm{m}, \mathrm{V}_{0}, \sigma_{\mathrm{u}}\right.$ and $\left.\sigma_{\min }\right)$ cannot be uniquely defined. The shape parameter $\mathrm{m}$ has also been shown by Milella and Bonora [17] to be a function of the notch tip geometry (or alternatively local triaxial stress state), so that for blunt notches in ferritic steels $\mathrm{m}$ is about 20 and decreases to 4 for sharp tip cracks. For pre-cracked specimens and for consistency between equations (1) and (2) we select $\mathrm{m}=\beta$, and calibrate the remaining parameters using the fracture toughness results for the as-received tests shown in Figure 2.

The Weibull stress $\left(\sigma_{w}\right)$ is a function of $V_{0}$ and $m$ and for a given value of $V_{0}$ the remaining parameters $\left(\sigma_{u}\right.$ and $\left.\sigma_{\min }\right)$ were determined by obtaining failure probabilities from the $\mathrm{FE}$ analysis that best matched the experimental as-received data for A533B steel. The distribution parameters are non-unique and for two values of $\mathrm{V}_{0}$ two sets (1 and 2) of the Weibull parameters, $\sigma_{\mathrm{u}}$ and $\sigma_{\min }$, were obtained. The results of this calibration study are illustrated in Figure 4 where the estimated probability of failure is shown for two sets of parameters. For set 1, with $V_{0}=0.01 \mathrm{~mm}^{3}$, the fitted values of $\sigma_{\mathrm{u}}$ and $\sigma_{\min }$ are 8.0 and $2.0 \mathrm{GPa}$ respectively. Similarly for set 2 , with $V_{0}=0.1 \mathrm{~mm}^{3}$ (ten times bigger), $\sigma_{\min }=1.0 \mathrm{GPa}$ and $\sigma_{\mathrm{u}}=4.5 \mathrm{GPa}$ also provided a close estimate of failure probability. 


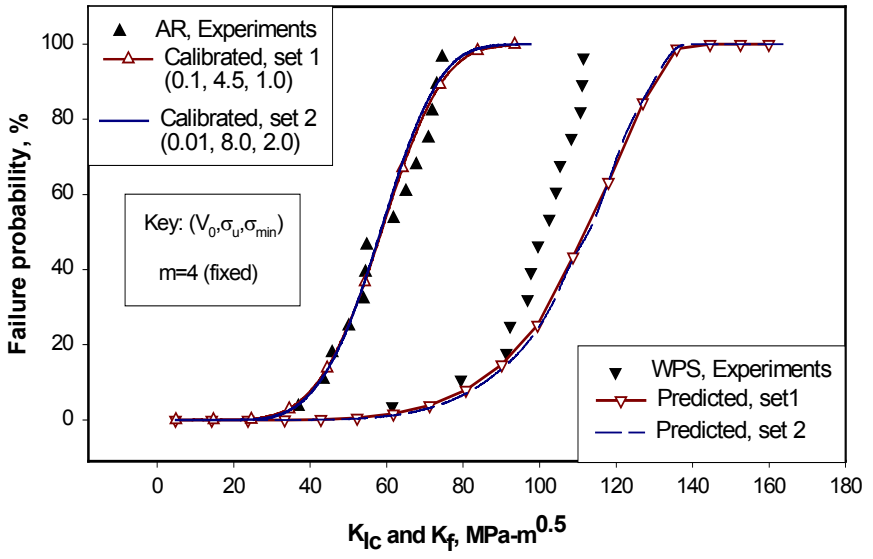

Fig. 4. Prediction of failure probability in the pre-cracked specimens for A533B steel at $-170^{\circ} \mathrm{C}$ following WPS

For the A508 steel RNB tests the as-received data were used to calibrate the Weibull parameters. Unlike the analysis for the precracked data, $\mathrm{V}_{0}$ was fixed equal to $0.001 \mathrm{~mm}^{3}$ and $\mathrm{m}$ was a free parameter. Initial estimates for the parameters were taken from ESIS. These did not provide a good calibration. However an improved calibration was obtained for A508 steel. The parameter values that provided the best agreement with experimental results are $m=24, \sigma_{\mathrm{u}}$ $=2.36 \mathrm{GPa}$ and $\sigma_{\min }=0.8 \mathrm{GPa}$. Using these values the estimated curve for probability of fracture for the RNB tests is shown in Figure 3.

\section{Simulation of WPS}

The sets of Weibull parameters were then used to predict the enhancement in cleavage fracture toughness following the LUCF cycle for both pre-cracked and RNB specimens. The WPS simulation was done by pre-loading and unloading using room temperature elasticplastic material properties. The simulation was then continued using the lower temperature elastic-plastic mechanical properties. The probability of failure was determined using the "Local" subroutine together with the calibrated Weibull parameters from the as-received fracture behaviour. It should be noted that the "Local" subroutine was used to determine $\mathrm{P}_{\mathrm{f}}$ only during the final reloading following WPS and not during the WPS. On reloading to fracture at low temperature the stress field in the newly developing plastic zone will be different from the as-received tests. This effect is presented later. A key feature in the "Local" analysis following WPS was to identify the plastic volume. We assumed that the initial plastic zone (arising from WPS) was not reactivated until the plastic strain on reloading exceeded the plastic strain arising from WPS.

\section{RESULTS}

\section{Probability of Failure}

The two sets of Weibull parameters, shown in Figure 4 with $m=4$, determined from the calibration studies for the pre-cracked specimens of A533 steel, were used to predict failure of probability following WPS. The resulting predictions for WPS are also shown in Figure 4. The local approach predicts significant improvement in toughness following proof loading and overall overestimates the fracture toughness compared to experimental results, especially for the higher fracture loads. Both sets of Weibull parameters provide essentially identical results.

The results from the WPS simulations for A508 steel RNB specimens are shown in Figure 3. The simulations tend to over predict the effect of WPS in improving the fracture stress at low stresses. Nevertheless predictions compare well with the experimental results. It is particularly interesting to note that the model predicts the shift in fracture stress corresponding to lower experimental fracture stresses and yet for higher fracture stresses predicts no improvement as suggested by the experimental data.

\section{Local Crack Tip Stresses}

We can gain an understanding of the influence of WPS by examining the notch and near crack tip stresses. Figures 5 and 6 show the distributions of the normal stress $\left(\sigma_{\mathrm{yy}}\right)$ at onset of brittle failure in both specimens. For the pre-cracked specimen the stress distribution corresponds to a combined elastic-plastic strain state ahead of the crack tip. In contrast for the RNB specimen the stress distribution is associated with a fully plastic state across the net section. Also shown in Figures 5 and 6 are stress distributions at lower load levels.

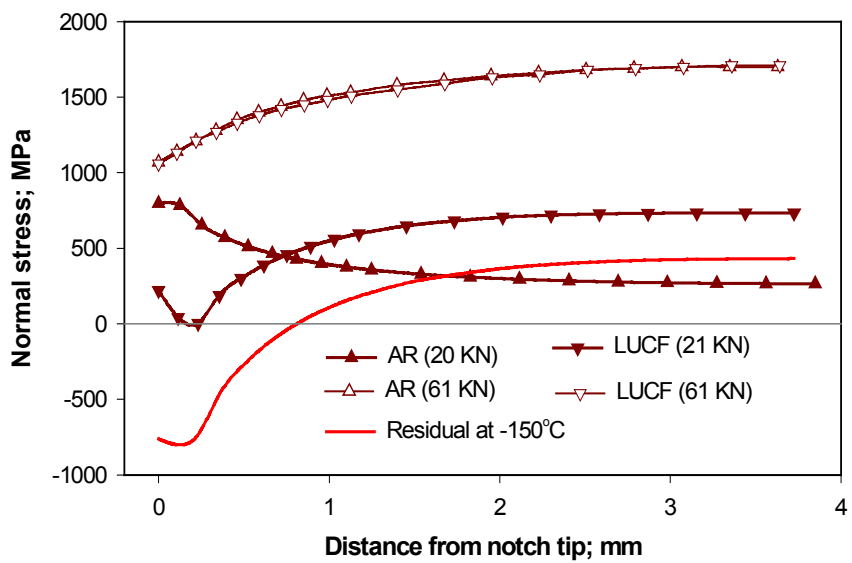

Fig. 5. Normal stress $\left(\sigma_{\mathrm{yy}}\right)$ distribution across the section (at notch tip) in RNB specimen for A508 steel at $-150^{\circ} \mathrm{C}$ (AR and LUCF)

When both specimens are subjected to WPS and unloading the FE analysis revealed residual stress distributions ahead of the crack and notch tips. Results shown in Figures 5 and 6 show that a compressive residual stress extends to distances ahead of the crack and notch tip of about $1 \mathrm{~mm}$. On reloading at lower temperatures the local residual stress combined with the stress from the applied loading is lower than the stress associated with applied loading alone. This is particularly the case near to the crack and notch tips. Further away the combined stress is greater than that for applied loading alone. For the pre-cracked specimen a greater applied load $(70 \mathrm{KN})$ is required after WPS to match the stress distribution for the failure load $(58 \mathrm{KN})$ in the 
as-received state. In contrast for the RNB specimen at an applied load $(61 \mathrm{KN})$ after WPS, equal to the applied load for failure in the asreceived state, the stress distribution ahead of the notch tip is essentially the same as that without WPS. There is little or no influence of the residual stress following WPS for the RNB at this load.

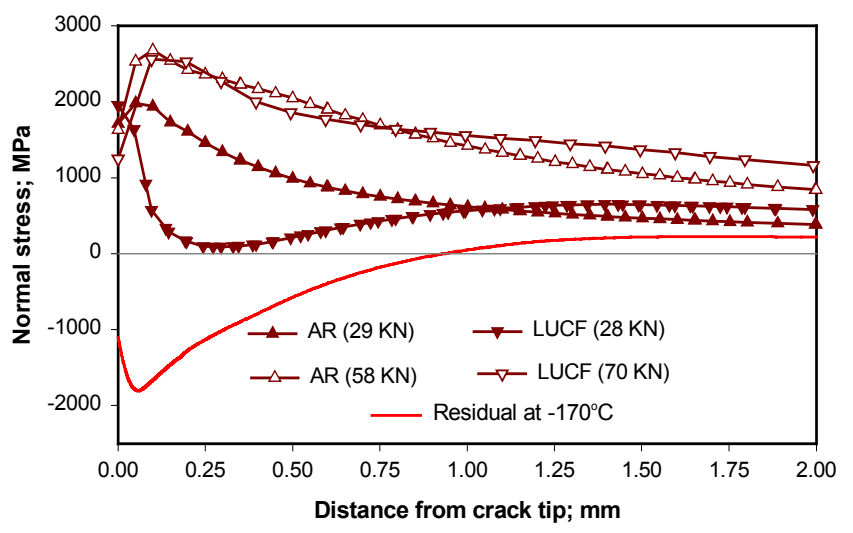

Fig. 6. Normal stress $\left(\sigma_{\mathrm{yy}}\right)$ distribution ahead of the crack tip for A533B steel at $-170^{\circ} \mathrm{C}(\mathrm{AR}$ and LUC - F)

\section{CONCLUDING REMARKS}

This work and others [16] demonstrate that the parameters required to provide matching of probability of failure with experimental results from fracture toughness tests are not unique. In this work for pre-cracked specimens we have, for consistency, provided a Weibull modulus $m$ that matches the modulus $\beta$ in equation (1). In earlier work by Gao et al [16] it was suggested that better estimates of the Weibull parameters would be attained from two data sets corresponding to two different levels of "constraint". This is the same as having two sets of specimens with different local stress distributions. The introduction of crack tip residual stress in precracked specimens using WPS also provides a different local stress field. Here we have not used the approach developed by Gao et al [16]. Rather we provide a calibrated set of Weibull parameters using only the as-received data and then use the same parameters to predict the effects of WPS for the LUCF cycle. The predictions in Figure 4 overestimate the increase in toughness particularly for higher load levels (higher $\mathrm{K}_{\mathrm{f}}$ ).

As was noted earlier empirical curve fitting of the experimental results (shown in Figure 2) revealed that with $K_{\min }=0$ the shape parameter, $\beta$ changed from about 5 to 11 . This indicates that following WPS the toughness distribution becomes narrower. This is also evident in the results using RNB tests shown in Figure 3. However in the FE analysis the shape parameter $\mathrm{m}$ for the local analysis of the pre-cracked specimen was selected to be equal to $\beta$ $(=4)$ for the as-received state, while following WPS we assumed that $\mathrm{m}$ remained unchanged. The assumption that $\mathrm{m}$ remains unchanged appears to be appropriate for the RNB simulations (with $\mathrm{m}=24$ ) but not for the pre-cracked simulations. In the former case, an improvement in toughness is obtained at low fracture loads because of the presence of residual stress. At higher loads and for conditions corresponding to wide spread plasticity the influence of the residual stress is negligible. This is because the residual stresses are completely removed through plastic deformation which is similar to the argument given by Curry [8].

Earlier work by Millela [17] showed that the shape parameter was a function of local triaxial stress state with $m$ increasing with decreasing triaxiality. The presence of residual stress and crack tip blunting after WPS alters the triaxiality. This feature has not been included in this study and will require further investigation.

\section{REFERENCES}

[1] Pickles, B.W., Cowen, A., (1983), "A review of warm prestressing studies," Int. J. Pres. Ves. \& Piping, 14, pp.95-131.

[2]Smith, D.J., Garwood, S.J., (1990), "The significance of prior overload on fracture resistance- a critical review," Int. J. Pres. Ves. \& Piping, 41, pp.255-296.

[3] Reed, P.A.S., Knott, J.F. (1996), "Investigation of the Role of Residual Stress in the Warm Pre-stress (WPS) Effect Part IExperimental," Fatigue Fract. Engng. Matr. Struct., 19(4), pp.485-500. [4] Reed, P.A.S., Knott, J.F. (1996), "Investigation of the Role of Residual Stress in the Warm Pre-stress (WPS) Effect Part IExperimental," Fatigue Fract. Engng. Matr. Struct., 19(4), pp.501-513. [5] Fowler, H., (1998), "The influence of warm pre-stressing and proof loading on the cleavage fracture toughness of ferritic steels", Ph.D. thesis, University of Bristol, UK.

[6] Smith, D.J., Garwood, S.J., (1990), "Experimental Study of Effects of Prior Overload on Fracture Toughness of A533B Steel," Int. J. Pres. Ves. \& Piping, 41, pp.297-331.

[7] Fowler, H., Smith, D.J., Bell K., "Scatter in Cleavage Fracture Toughness Following Proof Loading," In: advances in fracture research, Proc. $9^{\text {th }}$ Int. Conf. Fracture (ICF 9), 5,pp. 2519-2526.

[8] Curry, D.A., (1981), "A Micro-mechanistic Approach to the Warm Pre-stressing of Ferritic Steels," Int. J. Fracture, 17(3), pp. 335-343.

[9] Chell, G.G., (1980), "Some Fracture Mechanics Applications Of Warm Pre-stressing To Pressure Vessels," In: Proc. $4^{\text {th }}$ Int. Conf. Pres. Ves. Technology, IMechE, pp. 117-124.

[10] Beremin, F.M.,(1981), "Numerical modelling of warm pre-stress effect using a damage function for cleavage fracture," Procs $5^{\text {th }}$ in Conf Fracture, ICF5, Vol 2, Oxford Pergamon.

[11] Beremin, F.M., (1983), "A local criterion for cleavage fracture of a nuclear pressure vessel steel," J. Metall. Trans. 14A, pp. 2277-2287.

[12] Catherine C.S., Poussard C., (2000) "Prediction of cleavage toughness on CT specimen, Numerical Round Robin on MicroMechanical Models," ESIS TC 8.

[13] Swankie, T.D., (1999), "The role of shear and constraint in mixed mode fracture", Ph.D. thesis, University of Bristol, UK.

[14] Bergman, B., (1984), "On the estimation of Weibull modulus," J. Mat. Sci. Lett.3, pp. 689-692.

[15] Hibbit, Karlsson and Sorenson Inc., (2001) ABAQUS Users Manuals (Version 6.2), HKS Inc., 1080 Main Street, Pawtucket, RI 02680-4847, USA.

[16] Gao, X., et al (1998), "Calibration of Weibull stress parameters using fracture toughness data," Int. J. Fracture 92, pp175-200.

[17] Milella, P.P., Bonora, N., (2000), "On the dependence of the weibull exponent on geometry and loading conditions and its implications on the fracture toughness probability curve using a local criterion," Int. J. Fracture, 104, pp.71-87. 